\title{
Ein Beitrag zu den Reactionen der Pflanzengifte.
}

\author{
Von 0. Pape, d. Z. in Giessen.
}

Die seit einer Reihe von Jahren angewandten concentrirten Säuren zur individuellen Erkennung der Alkaloïde und Glucoside haben bei ihrer Anwendung auf besagte Körper den Nachtheil, Farbenreactionen hervorzurufen, welche an grosser Unbeständigkeit leiden. Der Grund hiervon liegt in der complicirten Structur der Alkaloïde, welche durch den Effect der concentrirten Säuren eine tiefgehende und rasche Zersetzung erleiden. Letztere kann unter Zuziehung des Stärkekörpers (Amylum Tritici) einigermaassen bei einem grossen Theil der Alkaloïde verhindert werden.

Digitalin, die hellgelbe nicht krystallinische Form, welche in den Apotheken und Chemikalienhandlungen gebräuchlich ist, verrieben mit der zehnfachen Menge Stärke zeigt folgende Reactionen: Durch einige Tropfen concentrirte $\mathrm{H}^{2} \mathrm{SQ}^{4}$, so viel dass die Masse Breiconsistenz behält, wird der Stärkekörper schwarzbraun, fügt man dann einige Tropfen $\mathrm{HNO}^{3}$ hinzu und agitirt mit einem Glasstäbchen, so erscheint durch Schlemmen mit $\mathrm{H}^{2} \theta$ der Stärkekörper als tiefgrüne Masse.

Bei Anwendung von Rohrzucker erscheinen dieselben Reactionen, nur geht durch das Hinzufügen von $\mathrm{H}^{2} \theta$ der grüne Körper leicht in Lösung und verschwindet so dem Auge. Beide Reactionen sind zur Erkennung sehr geeignet.

Digitalinum crystallisatum purum mit der zehnfachen Menge Stärke gemengt zeigt nachstehende Reactionen: Einige Tropfen $\mathrm{H}^{2} \mathrm{~S} \theta^{4}$ rufen eine dunkelbraune Farbe hervor. Durch $\mathrm{HNO}^{3}$ und endliches Schlemmen mit $\mathrm{H}^{2} \mathrm{O}$ bleibt ein mattgrüner Stärkekörper zurück.

Dieselbe Menge Digitalinum crystallisatum mit Rohrzucker zerrieben, zeigt folgende Farbereactionen: Dünn vertheilte Schichten erscheinen durch $\mathrm{H}^{2} \mathrm{SQ}^{4}$ zuerst gelb, darauf orange; durch Agitiren endlich tief braun. Durch Hinzufügen von $H^{2} \theta$ ist leider nicht immer eine grüne Reaction zu beobachten, da der Körper in Wasser löslich ist und verschwindet. 
Stärke - wie Rohrzucker-Reactionen sind indessen beide charakteristisch. Digitalinum crystallisatum mit der gleichen Menge Stärke und $\mathrm{H}^{2} S Q^{4}$ braun gefärbt, lässt auch durch $\mathrm{HCl}$ und endlich $\mathrm{H}^{2} \theta$ eine grüne Masse erscheinen. Das gelbe, nicht krystallinische Digitalin zeigt bei derselben Anwendung der Stärke, $\mathrm{H}^{2} \mathrm{~S} \theta^{4}$, dann $\mathrm{HCl}$, nicht vielleicht erst $\mathrm{HCl}$ und dann $\mathrm{H}^{2} \mathrm{~S} \theta^{4}$, was eine stiurmische Chlorwasserstoffentwickelung zur Folge hätte, die nämlichen Reactionen, wie Digitalinum purum, nur tritt beim gelben Digitalin nach der Hinzufügung des Wassers der grüne Körper intensiver auf.

Veratrin mit der zehnfachen Menge Stärke gemengt und einigen Tropfen $\mathrm{H}^{2} \mathrm{SQ}^{4}$ versetzt, erscheint b ra ung e lb, durch Umrühren vermittelst eines Glasstabes braunroth. Durch $\mathrm{HNO}^{3}$ und hierauf $\mathrm{H}^{2} \mathrm{O}$ wird der Stärkekörper gelb. Morphin erleidet in der Stärkemischung $1: 10$ durch $\Pi^{2} S \theta^{4}$ keine Veränderung, welche durch Färbung sich zeigte; setzt man aber hierauf einige Tropfen $\mathrm{HN} \Theta^{3}$ hinzu und agitirt, so wird der Stärkekörper schön orangefarbig. Veratrin - wie Morphinreaction sind durch ihre ausgesprochenen Farben leicht zu erkennen.

Es lässt sich die Stärke ferner anwenden bei Codein, Narcotin, Narcein, Brucin, nicht bei Strychnin, mit denselben Säuren.

Bei angefuhrten Reactionen wurden die Säuren in concentrirter Form, und die Alkaloïde mit denselben im trocknen Zustande in einem Porzellanmörser zusammengebracht.

\section{Jittheilnngen aus dem Laboratorium}

von E. Reichardt.

Der rohe Schellack und eine neue, darinenthaltene, stickstoffreiche Säure;

von Dr. J. Hertz, Assistenten an der Versuchsstation zu Jena.

Die nachstehende Arbeit wurde durch eine Sendung des Herrn Hofapotheker Koeppen in Rudolstadt veranlasst. Der ebendaselbst wohnende Consul $\mathrm{Damm}$, welcher längere 